\title{
Optimization of Cutting Parameters in Turning Operation by Using Taguchi Method
}

\author{
S. Amarnath Reddy ${ }^{1}$, Mr. J. Sree Hari ${ }^{2}$ \\ ${ }^{1}$ P.G Scholar, ${ }^{2}$ Assistant Professor \\ Sri Venkateswara Institute of Technology, Anantapur, Andhra Pradesh, India
}

\begin{abstract}
In the present work, the work piece material taken is chrome-moly alloy steel. This is a hard material having hardness $48 \mathrm{HRC}$. This alloy steel bears high temperature and high pressure and its tensile strength is high. It is very resistive to corrosion and temperature. For these useful properties it is used in power generation industry and petrochemical industry. Also it is used to make pressure vessels.
\end{abstract}

For machining of work piece the insert chosen is Tic coated carbide insert. Three factors speed, feed and depth of cut were taken at three levels low, medium and high. By the L27 orthogonal design twenty seven runs of experiments were performed. For each run of experiment the time of cut was 2 minutes.

The output responses measured were surface roughness, power consumption, chip reduction coefficient and tool wear (flank wear). All the output responses were analyzed by $\mathrm{SN}$ ratio, analysis of variance, and response table. The criteria chosen here is smaller the better and the method applied is Cutting tools.

\section{INTRODUCTION}

Hard machining means machining of parts whose hardness is more than 45HRC but actual hard machining process involves hardness of 58HRC to 68HRC.The work piece materials used in hard machining are hardened alloy steel, tool steels, case - hardened steels, nitride irons, hard - chrome coated steels and heat - treated powder metallurgical parts.

\section{Limitations of Hard Machining}

$>$ For hard turning the length to diameter (L/D) ratio should be small. For unsupported work pieces it should not be more than $4: 1$ because long thin parts will induce chatter due to high cutting pressure.

In hard machining, a very thin layer of material which is harder than inner material is formed which is known as white layer. With tool wear increase its thickness increases. White layer is commonly formed on bearing steel and makes problem for bearing races which receive high contact stresses. The white layer causes bearing failure.

\section{Features in Which Hard Machining Is Different} From Conventional Machining

When work material gets fractured chip in the form of saw tooth is formed. Within the range of shear strain crack is formed at the free surface of the work piece.

Because of adiabatic shear segmental chips are formed in materials which are difficult to machine and its cross section is similar to saw-toothed chip formed in hard machining but these two chips are not same because they are produced due to different mechanisms.

Radial (thrust) component of the cutting force is greater than tangential (power) component cutting force in case of hard machining. The difference between these two forces increases with increase of flank wear.

\section{Factors Distinguishing Hard Machining}

To distinguish between hard machining conventional machining differences in energy balance should be analyzed. The formula for balance of energy in metal cutting is given by $\mathrm{Pc}=\mathrm{Fc} . \mathrm{V}=\mathrm{Ppd}+\mathrm{Pfr}+\mathrm{Pjf}+\mathrm{Pch}$ Where $\mathrm{Fc}=$ power (tangential) component of the cutting force. 
$\mathrm{V}=$ cutting speed

Ppd = power consumed due to plastic deformation

$\mathrm{Pfr}=$ power used on tool chip interface

$\mathrm{Pjf}=$ power used on tool work piece interface

Pch $=$ power used due to formation of new surfaces

\section{Hard Turning}

Hard turning is a process which eliminates the requirements of grinding operation. A proper hard turning process gives surface finish $\mathrm{Ra} 0.4$ to 0.8 micrometer, roundness about 2-5 micrometer and diameter tolerance +/-3-7micrometre. Hard turning can be performed by that machine which soft turning is done..

\section{Causes of Tool wear}

There are two interrelated causes for tool wear are mechanical abrasion and thermal erosion. Although these two actions take place simultaneously, the role of each varies for various cutting conditions. Mechanical wear is dominant when low cutting speeds are used or when the work piece possesses high machinability. Thermal wear prevails when high cutting speeds are used with work pieces having low mach inability.

\section{Mechanisms of Tool Wear}

Evidence indicates that wear is a complex phenomenon and is influenced by many factors. The causes of wear neither behave in the same manner, nor they always affect wear to the same degree under similar cutting conditions.

$>$ Abrasive action of hard particles contained in the work material.

$>$ Plastic deformation of the cutting edge.

$>$ Chemical decomposition of the cutting tool contact surfaces.

\section{Tool Wear and Surface Roughness- Overview}

Surface Roughness: Due to the increased knowledge and constant improvement of the surface textures gives the present machine age a great advancement. Due to the demand of greater strength and bearing loads smoother and harder surfaces are needed. Due to conditions not being ideal the surface being produced will have some irregularities and these irregularities can be classified into four categories given as follows:-

> First order: - This type of irregularities is arising due to inaccuracies in the machine tool itself for example lack of straightness of guide ways on which tool post is moving. Irregularities produced due to deformation of work under the action of cutting forces and the weight of the material are also included in this category.

Second order: - This order of irregularities is caused due to vibration of any kind such as chatter marks.

> Third order:- If the machine is perfect and completely free of vibrations still some irregularities are caused by machining due to characteristics of the process. For example feed mark of cutting tool.

Fourth order: - This type of irregularities is arised due to rupture of the material during the separation of the chip.

\section{Terms Used In Surface Finish}

Roughness: - This is produced due to irregular structures in the surface roughness which is resulted from the inherent action of production process.

Waviness: - This is produced due to deflection in work piece or machine vibrations produced in machine.

Flaws: - The irregularities which are produced at one place or infrequently in widely varying intervals in a surface are called flaws.

$>$ Centre line:-The line about which roughness is measured.

Traversing length: - It is the length of the profile necessary for the evaluation of the surface roughness parameters. The traversing length includes one or more sampling lengths.

\section{Methods of Measuring Surface Roughness}

There are two methods of measuring the finish of machined part. They are:-

1. Surface inspection by comparison methods

2. instrument measurements

\section{Tool Wear in Turning}

A constant cutting force is acting in turning operation and turning is a continuous process. A high temperature is produced at the tool/chip interface because of constant heat derived from shear deformation energy and friction. The principal wear factor in turning is high temperature at the tool rake face. The temperature is around 600 degree for austenitic steels, super alloys or titanium alloys. Tool wear mechanisms in turning are basically four types in turning. They are as follows:-

$>$ Crater wear

$>$ Notch wear 
$>$ Flank wear

$>$ Adhesion

\section{Work piece material:}

The work piece is chrome-moly alloy which is prepared at cast profile private limited, Kalunga. Its length is $600 \mathrm{~mm}$ and diameter is $50 \mathrm{~mm}$. It is heat treated to make its hardness up to 48 HRC The photograph of work piece material and chemical composition of the CR-MO alloy is given below in fig.

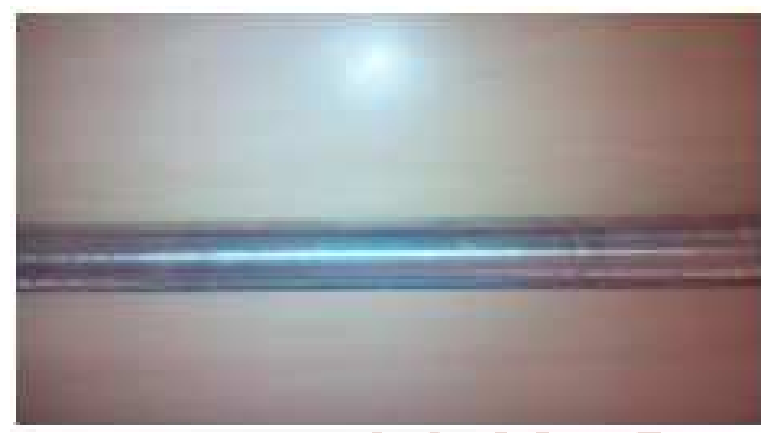

Fig: Work piece material (Cr-Mo round bar)

Dimension of Cr-Mo alloy:

Length of bar $=600 \mathrm{~mm}$

Diameter of bar $=50 \mathrm{~mm}$

Hardness of material $=48 \mathrm{HRC}$

\section{Chemical composition of Cr-Mo alloy}

\begin{tabular}{|c|c|c|c|}
\hline Carbon & Mn & Cr & Mo \\
\hline 0.15 max & $0.3-0.6$ & $4.0-6.0$ & $0.44-0.65$ \\
\hline
\end{tabular}

\section{Cutting inserts}

Cutting inserts used in this experiment are four in number. Each insert has eight edges so for 27 experiment all eight edges of first three are used and three edges of last insert is used. The specification of insert is SNMG 120408. The inserts are Tic coated carbide inserts.

\section{Experimental procedure:}

The rough work piece of chrome-moly alloy bought from cast profile Ltd, kalunga is first turned to clear the rough skin using uncoated carbide insert. The final diameter of the work piece is made $50 \mathrm{~mm}$. The two ends of the work piece are faced and centering is done using carbide centre drill. The final length of the work piece was made $600 \mathrm{~mm}$.

The purpose of this experiment is to find the effect of speed, feed and depth of cut on output responses like surface roughness, power consumption, chip reduction coefficient and tool wear. The levels of speed, feed and depth of cut are three each which is given in table. Total 27 experiments were done according to L27 orthogonal array. The work piece was held rigidly on the lathe and for each set of the data work piece is turned for 2 minutes so 27 cuts were made on the work piece which is shown in Fig.

The surface roughness component (Ra) was measured using Taylor/Hobson (sutronic 3+) for 27 cuts. The power consumed in machining was measured by wattmeter connected to the Lathe machine. The wattmeter gave the reading of yoltage (V), current (I) and power factor $(\cos \phi)$ for each of the runs of the experiment. The power consumption can be given by formula $\mathrm{P}=$ V.I. $\cos \phi$. The four inserts used for the experiment are shown in Fig.

Each insert has eight edges so all eight edges of first three inserts and three edges of last one were used for 27 experimental runs. The chips were collected for 27 experiments and their thickness were calculated using micrometer shown in Fig-4.6. The chip reduction coefficient can be given by formula below. Unreformed chip thickness $=\mathrm{f} \sin \mathrm{Kr}$ where $\mathrm{f}$ is the feed and $\mathrm{kr}$ is the principal cutting edge.

The tables for power and chip reduction co-efficient

\begin{tabular}{|c|c|c|c|c|c|c|c|c|c|}
\hline $\begin{array}{c}\text { Run } \\
\text { no }\end{array}$ & $\begin{array}{c}\text { Speed In } \\
\text { rpm }\end{array}$ & $\begin{array}{c}\text { fed in } \\
\text { mm/rev }\end{array}$ & $\begin{array}{c}\text { d.o.c in } \\
\text { mmm }\end{array}$ & v in volt & I in amp & P.F & run no & $\begin{array}{c}\text { speed in } \\
\text { rpm }\end{array}$ & $\begin{array}{c}\text { fed in } \\
\text { mm/rev }\end{array}$ \\
\hline 1 & 250 & 0.1 & 0.3 & 410 & 4.7 & 0.21 & 113.0586 & 125.017 & 136.938143 \\
\hline 2 & 250 & 0.1 & 0.5 & 409.3 & 4.81 & 0.31 & 82.967143 & 79.88679 & 76.8064286 \\
\hline 3 & 250 & 0.1 & 1 & 400.8 & 4.42 & 0.28 & 80.14 & 76.61786 & 73.0957143 \\
\hline 4 & 250 & 0.13 & 0.3 & 411.4 & 4.72 & 0.2 & 82.865714 & 79.62679 & 76.3878571 \\
\hline 5 & 250 & 0.13 & 0.5 & 406.6 & 4.69 & 0.25 & 81.252857 & 77.73857 & 74.2242857 \\
\hline 6 & 250 & 0.13 & 1 & 401.5 & 4.53 & 0.3 & 79.541429 & 75.73179 & 71.9221429 \\
\hline 7 & 250 & 0.15 & 0.3 & 416 & 4.98 & 0.21 & 83.44 & 80.06286 & 76.6857143 \\
\hline 8 & 250 & 0.15 & 0.5 & 407.6 & 4.72 & 0.25 & 80.694286 & 76.89571 & 73.0971429 \\
\hline 9 & 250 & 0.15 & 1 & 410.2 & 4.81 & 0.3 & 81.29 & 77.48893 & 73.6878571 \\
\hline
\end{tabular}


International Journal of Trend in Scientific Research and Development (IJTSRD) ISSN: 2456-6470

\begin{tabular}{|l|l|l|l|l|l|l|l|l|l|}
\hline 10 & 420 & 0.1 & 0.3 & 415.6 & 4.81 & 0.25 & 58.132857 & 42.27107 & 26.4092857 \\
\hline 11 & 420 & 0.1 & 0.5 & 408.6 & 4.7 & 0.27 & 55.84 & 39.61536 & 23.3907143 \\
\hline 12 & 420 & 0.1 & 1 & 400.8 & 4.7 & 0.42 & 53.482857 & 36.88857 & 20.2942857 \\
\hline 13 & 420 & 0.13 & 0.3 & 415.7 & 4.92 & 0.24 & 0.491 & 0.07 & 0.577 \\
\hline 14 & 420 & 0.13 & 0.5 & 407.6 & 4.67 & 0.27 & 0.514 & 0.16 & 1.274 \\
\hline 15 & 420 & 0.13 & 1.0 & 403.1 & 4.78 & 0.43 & 0.830 & 0.26 & 2.070 \\
\hline 16 & 420 & 0.15 & 0.3 & 418.5 & 4.87 & 0.24 & 0.489 & 0.08 & 0.552 \\
\hline 17 & 420 & 0.15 & 0.5 & 408.6 & 4.78 & 0.32 & 0.624 & 0.20 & 1.380 \\
\hline 18 & 420 & 0.15 & 1.0 & 402.6 & 4.75 & 0.43 & 0.822 & 0.21 & 1.449 \\
\hline 19 & 710 & 0.1 & 0.3 & 417.0 & 5.06 & 0.31 & 0.654 & 0.09 & 0.724 \\
\hline 20 & 710 & 0.1 & 0.5 & 407.8 & 4.92 & 0.38 & 0.762 & 0.04 & 0.414 \\
\hline 21 & 710 & 0.1 & 1.0 & 401.5 & 5.01 & 0.58 & 1.166 & 0.11 & 1.138 \\
\hline 22 & 710 & 0.13 & 0.3 & 416.0 & 4.94 & 0.32 & 0.662 & 0.05 & 0.398 \\
\hline 23 & 710 & 0.13 & 0.5 & 410.6 & 4.98 & 0.40 & 0.818 & 0.12 & 0.955 \\
\hline 24 & 710 & 0.13 & 1.0 & 400.2 & 5.45 & 0.61 & 1.330 & 0.19 & 1.513 \\
\hline 25 & 710 & 0.15 & 0.3 & 412.3 & 4.96 & 0.41 & 0.838 & 0.15 & 1.035 \\
\hline 26 & 710 & 0.15 & 0.5 & 407.8 & 4.78 & 0.39 & 0.760 & 0.09 & 0.621 \\
\hline 27 & 710 & 0.15 & 1.0 & 402.3 & 5.02 & 0.49 & 0.989 & 0.22 & 1.518 \\
\hline
\end{tabular}

\section{Chip collected during experiment}

The chips were collected during all 27 experiments and their thickness were measured using micrometer shown in Fig. The chip reduction co-efficient was calculated for each chip. Unreformed chip thickness $=$ $\mathrm{f} \sin \mathrm{Kr}$ where $\mathrm{f}$ is the feed and $\mathrm{kr}$ is the principal cutting edge of the insert. The photographs of all the chips were shown below in fig.
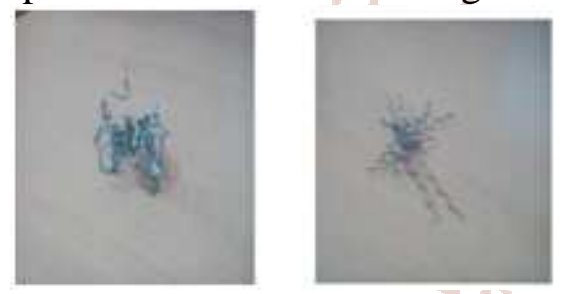

\section{Photographs of tool wears:-}

The photographs of 27 tool wears of edges of inserts taken by stereo zoom microscope is given in Fig.
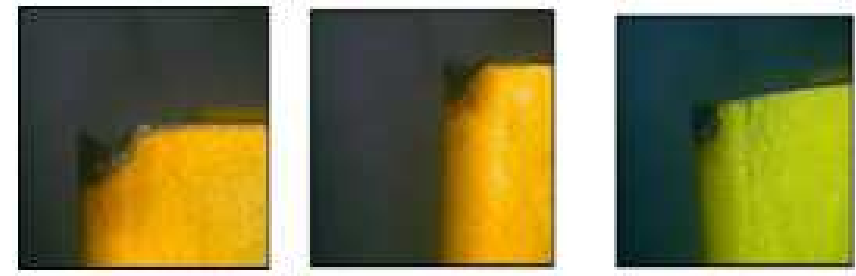

\section{Results and Discussion}

Main effect plots for surface roughness:-

The Fig shows the main effects for surface roughness that means the graphs of speed vs. mean of $\mathrm{S} / \mathrm{N}$ ratios of surface roughness, feed vs. mean of $\mathrm{S} / \mathrm{N}$ ratios of surface roughness, depth of cut vs. mean of $\mathrm{S} / \mathrm{N}$ ratios of surface roughness for lower is better. As the speed increases the mean of $\mathrm{S} / \mathrm{N}$ ratios decreases that means good surface finish is obtained with increase in speed. From the graph it is clear that as the feed increases surface roughness decreases that means increase in feed also gives good surface finish. From the graph it is clear that as the depth of cut increases first surface roughness decreases upto some value and then increases. From three graphs the slope of feed vs. mean of S/N ratio graph is largest, depth of cut vs. mean of $\mathrm{S} / \mathrm{N}$ ratio graph possesses second largest slope so surface roughness is significantly affected by feed and depth of cut but cutting speed has not significant effect on surface roughness.

Table: Values of Predicted Surface Roughness and error

\begin{tabular}{|c|c|c|c|c|c|c|}
\hline No of Experiments & $\begin{array}{c}\text { Speed N } \\
(\mathbf{r p m})\end{array}$ & $\begin{array}{c}\text { Feed } \\
(\mathbf{m} \mathbf{m} / \mathbf{r e v})\end{array}$ & $\begin{array}{c}\text { D.0.C } \\
(\mathbf{m m})\end{array}$ & $\begin{array}{c}\text { Experimental } \\
\mathbf{R a}(\boldsymbol{\mu} \mathbf{m})\end{array}$ & $\begin{array}{c}\text { Predicted } \\
\mathbf{R a}(\boldsymbol{\mu} \mathbf{m})\end{array}$ & Error \\
\hline 1 & 100 & 0.14 & 0.5 & 4.98 & 4.9695 & 0.0105 \\
\hline 2 & 100 & 0.14 & 1 & 5.3 & 5.249 & 0.051 \\
\hline 3 & 100 & 0.14 & 1.5 & 5.44 & 5.5285 & -0.0885 \\
\hline 4 & 100 & 0.15 & 0.5 & 4.49 & 4.6535 & -0.1635 \\
\hline
\end{tabular}


International Journal of Trend in Scientific Research and Development (IJTSRD) ISSN: 2456-6470

\begin{tabular}{|c|c|c|c|c|c|c|}
\hline 5 & 100 & 0.15 & 1 & 5.01 & 4.933 & 0.077 \\
\hline 6 & 100 & 0.15 & 1.5 & 5.34 & 5.2125 & 0.1275 \\
\hline 7 & 100 & 0.16 & 0.5 & 4.33 & 4.3375 & -0.0075 \\
\hline 8 & 100 & 0.16 & 1 & 4.59 & 4.617 & -0.027 \\
\hline 9 & 100 & 0.16 & 1.5 & 4.88 & 4.8965 & -0.0165 \\
\hline 10 & 360 & 0.14 & 0.5 & 3.81 & 3.7319 & 0.0781 \\
\hline 11 & 360 & 0.14 & 1 & 3.97 & 4.0114 & -0.0414 \\
\hline 12 & 360 & 0.14 & 1.5 & 4.28 & 4.2909 & -0.0109 \\
\hline 13 & 360 & 0.15 & 0.5 & 3.46 & 3.4159 & 0.0441 \\
\hline 14 & 360 & 0.15 & 1 & 3.69 & 3.6954 & -0.0054 \\
\hline 15 & 360 & 0.15 & 1.5 & 4.01 & 3.9749 & 0.0351 \\
\hline 16 & 360 & 0.16 & 0.5 & 3.15 & 3.0999 & 0.0501 \\
\hline 17 & 360 & 0.16 & 1 & 3.41 & 3.3794 & 0.0306 \\
\hline 18 & 360 & 0.16 & 1.5 & 3.66 & 3.6589 & 0.0011 \\
\hline 19 & 560 & 0.14 & 0.5 & 2.73 & 2.7799 & -0.0499 \\
\hline 20 & 560 & 0.14 & 1 & 3.11 & 3.0594 & 0.0506 \\
\hline 21 & 560 & 0.14 & 1.5 & 3.37 & 3.3389 & 0.0311 \\
\hline 22 & 560 & 0.15 & 0.5 & 2.42 & 2.4639 & -0.0439 \\
\hline 23 & 560 & 0.15 & 1 & 2.73 & 2.7434 & -0.0134 \\
\hline 24 & 560 & 0.15 & 1.5 & 2.98 & 3.0229 & -0.0429 \\
\hline 25 & 560 & 0.16 & 0.5 & 2.18 & 2.1479 & 0.0321 \\
\hline 26 & 560 & 0.16 & 1 & 2.49 & 2.4274 & 0.0626 \\
\hline 27 & 560 & 0.16 & 1.5 & 2.62 & 2.7069 & -0.0869 \\
\hline & & Average error $=0.047411$ & & & \\
\hline
\end{tabular}

Simulations are conducted for aluminum and coated carbide tool couple. In the simulations $5^{0}$ rake angle, $300 \mathrm{~m} / \mathrm{min}$ cutting speed, $0.1 \mathrm{~mm} / \mathrm{rev}$ federate are selected with varying inclination angle. The sliding friction coefficients calibrated from the orthogonal cutting tests are used during the simulations. As the sliding friction coefficient for Mild Steel with coated carbide tool varies with the chip velocity, we would also like to see a similar effect on the friction behavior due to the inclination angle.

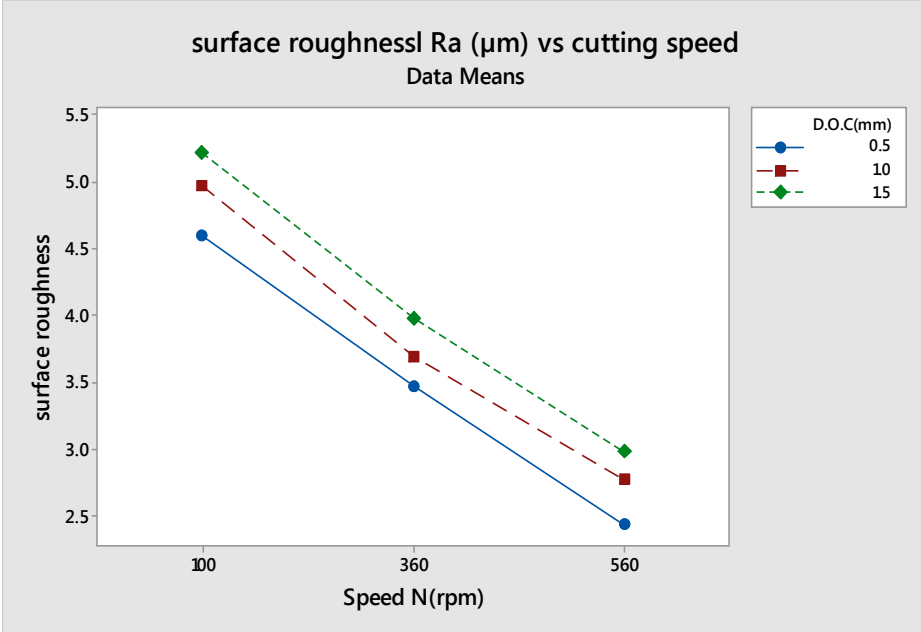

Surface roughness Vs cutting speed

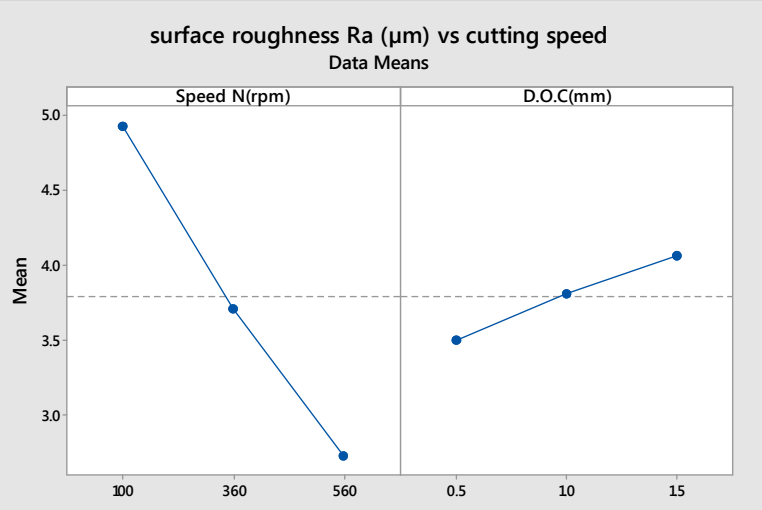

Means of plots for Surface roughness Vs Cutting speed

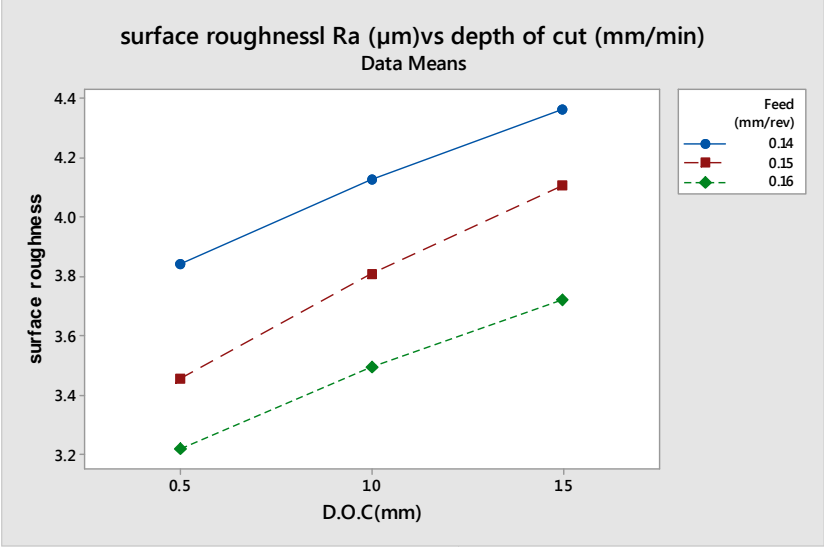

Surface roughness Vs Depth of cut 
CERAMICS for power consumption

\begin{tabular}{|c|c|c|c|c|c|c|}
\hline Source & DF & Seq. SS & Adj. SS & Adj. MS & F & P \\
\hline $\mathrm{V}$ & 2 & 113.444 & 113.444 & 56.7221 & 54.04 & 0.000 \\
\hline $\mathrm{F}$ & 2 & 0.419 & 0.419 & 0.2096 & 0.20 & 0.823 \\
\hline $\mathrm{D}$ & 2 & 62.341 & 62.341 & 31.1705 & 29.70 & 0.000 \\
\hline $\mathrm{V}^{*} \mathrm{f}$ & 4 & 1.471 & 1.471 & 0.3676 & 0.35 & 0.837 \\
\hline $\mathrm{V}^{*} \mathrm{~d}$ & 4 & 9.184 & 9.184 & 2.2961 & 2.19 & 0.161 \\
\hline $\mathrm{f}^{*} \mathrm{~d}$ & 4 & 2.865 & 2.865 & 0.7162 & 0.68 & 0.624 \\
\hline Residual & 8 & 8.397 & 8.397 & 1.0496 & & \\
\hline Total & 26 & 198.121 & & & & \\
\hline
\end{tabular}

Response table for $\mathrm{S} / \mathrm{N}$ ratios of power

\begin{tabular}{|c|c|c|c|}
\hline Level & Cutting speed & Feed rate & Depth of cut \\
\hline 1 & 6.260 & 4.080 & 5.614 \\
\hline 2 & 4.373 & 4.041 & 4.355 \\
\hline 3 & 1.287 & 3.799 & 1.951 \\
\hline Delta & 4.973 & 0.282 & 3.633 \\
\hline Rank & 1 & 3 & 2 \\
\hline
\end{tabular}

\section{Conclusion and Future Work}

Based on experimental results presented and discussed, the following conclusions are drawn on the effect of cutting speed, feed and depth of cut on the performance of Tic coated carbide tool when machining Cr-Mo alloy.

The study of Main effect plots of surface roughness indicates that as speed increases mean of $\mathrm{SN}$ ratio decreases that means good surface finish is obtained with increase in speed. As the feed increase mean of $\mathrm{SN}$ ratio decreases that means good surface finish is obtained with increase in feed. As the depth of cut increases from $0.3 \mathrm{~mm}$ to $0.5 \mathrm{~mm}$ surface roughness decreases but when depth of cut increase from $0.5 \mathrm{~mm}$ to $1 \mathrm{~mm}$ surface roughness increases.

The slope of feed vs. mean of SN ratio is largest, depth of cut vs. mean of $\mathrm{SN}$ ratio has the second largest slope so feed and depth of cut affect the surface roughness significantly which is clear from Fstatistics of and rank of response table. So feed and depth of cut are dominant factors for surface roughness.

\section{References}

1. Dilbag Singh and P.Venkateswara Rao "A surface roughness prediction model for hard turning process" int. J. Adv. Manuf. Technol 32: 11151124.

2. Tugrul Ozel, Tsu-Kong Hsu, Erol Zeren “ Effects of Cutting edge geometry, work piece hardness, feed rate and cutting speed on surface roughness and forces in finish turning of hardened AISI H13 steel" int. J. Adv. Manuf.Technol 25 : 262-269.

3. B. Fnides, M.A Yallese, T. Mabrouki, J. F Rigal "Surface roughness model in turning hardened hot work steel using mixed ceramic tool" ISSN 13921207 Mechanika. Nr.3 (77).

4. Dr. G. Harinath Gowd, M. Gunasekhar Reddy, Bathina Sreenivasulu " Empiricalmodelling of hard turning process of Inconel using response surface surface methodology" Int.

5. J. of emerging technology and advanced engineering, ISSN 2250-2459, volume2, Issue 10.

6. K. Adersh Kumar et all " Optimisation of surface roughness in face turning operation in machining of EN-8" International Journal of Engineering Science and emerging technology Vol 2, issue-4, 807-812.

7. S. B. Salvi ET all "Analysis of of surface roughness in hard turning by using Taguchi method" international Journal of Engineering science and technology vol5, No-2.

8. F. Puh et all "optimisation of hard turning process parameters with PCBN tool based on the Cutting tools." Technical Gazette 19, 2, 415-419.

9. Ali Riza Motorcu "The optimisation of machining parameters using the Cutting tools. For surface roughness of AISI 8660 hardened alloy steel" Journal of mechanical Engineering 566, 391-401.

10. R. Ramanujam et all "Taguchi multi machining characteristics optimisation in turning of Al-15 SiCp composites using desirability function analysis" Journal of studies of manufacturing vol1-2010/Iss2-3 pp120-125. 